\title{
INTEGRATING PRINCIPLES OF EXCELLENCE AND OF SOCIALLY RESPONSIBLE ENTREPRENEURSHIP
}

\author{
Helena ČIERNA, Erika SUJOVÁ \\ Technical University in Zvolen
}

\begin{abstract}
:
Social responsibility is seen as an institutional innovation, which leads to a chance of social rules. Social responsibility also stimulates other types of innovation, which could work as feedback to keep or as a strategic change of social responsibility. The strategy for improvement of quality creates opportunities to identify and to learn from those who are farther along the road to exceptionality and have improved quality or their products and services by improving their organization. The initiative to improve quality of products and services by improving the organization has to be based on clearly defined principles that help define key functions that support organization's activities, required resources and serve as supporting tools to improve quality. For an organization to have long term and continuous success it needs to fulfill expectations of all stakeholders and as part of this we can discuss Corporate Social Responsibility - CSR. This includes behaviour of organizations that goes beyond the prescribed legislative requirements, but includes activities that benefit not only the organization itself, but also its employees and the public.
\end{abstract}

Key words: principle of exceptionality, social responsibility principle, model RET, corporate social responsibility, CSR

\section{INTRODUCTION}

In recent years the terms responsibility, corporate responsibility and socially responsible entrepreneurship and its influence on business and the markets in which companies operate, are used more frequently. Economic globalization introduces the need for social and environmental responsibility of economic subjects, especially enterprises and their actions. Impacts of industrial production on the environment, issues with unemployment, human rights breaches and various financial and corruption related scandals in national enterprises shifted the public's and international corporations 'focus to social responsibility and mainly to socially responsible businesses.

Increasing demands on productivity and effectiveness of enterprises generate hunger for implementation of more efficient management systems that consider a number of different processes and documents for a specific area. Business is prone to change. Each era has specific ethical values that people follow, which lead to ethical norms. Consequently, an economic system is always tied to a specific spiritual-cultural style of a given era. The result of this interaction is called culture.

Social responsibility in enterprises is not defined by a specific word; it is defined by a phrase. There is a plurality of possible explanations of this phrase. In Slovakia the idea of socially responsible entrepreneurship entered the market with entry of international corporations in the 1990s. First glimpses of socially responsible entrepreneurship are noticeable in ideas of social utopian Mark Owen from the UK, entrepreneur Andrew Carnegie from the US or Tomas and Jan Bata from former Czechoslovakia. They all were charismatic leaders who in their business endeavours included the need to increase visibility of loyalty.

Social responsibility of individuals and enterprises is becoming one of the most important themes. This area is becoming an important part of corporate strategies. The philosophy of socially responsible entrepreneurship is about development, ethics, morale, nature, and of hope of the current and future generations. Socially responsible entrepreneurship is a concept through which enterprises show their shared responsibility in their country and functionality of their society. Based on the main concept of socially responsible entrepreneurship, enterprises complement their traditional economic goals by including social and ethical goals, keeping in mind the environment, and based on this approach modify their visions and strategies. Social responsibility is a direction that alters a company's focus from short-term to long-term goals focusing on the optimal not on the maximum.

\section{MANAGEMENT PRINCIPLES AND CONCEPTS}

For any management system to be beneficial for an organization, it has to be based on a good foundation. The term good foundation we currently understand as principles that represent lasting values, which are the building blocks of modern management. The term "principle 
"means a basic rule, an initial thought and a strategic rule on which any management system can be built and developed. For the purpose of this article, we are focusing on principles and their influence on quality management systems. Even though various quality management system models have obvious and understandable differences, based on understanding and structure of these principles we can state that currently there are eleven, more specifically eight, principles to effectively manage quality management systems in organizations. As Nenadal (1) stated, for effective functioning of a quality management system in an organization, there are eleven generally respected basic principled. They are the following:

1. Customer focus

2. Leadership

3. Involvement of people

4. Learning

5. Flexibility

6. Process approach

7. System approach to management

8. Continuous improvement

9. Factual approach to decision making

10. Mutual beneficial supplier relationships

11. Social responsibility

The order of principles is no relevant. For our article we are focusing on principle no. 11, Social Responsibility. Below is a brief description of the other principles, only for information. The customer is a person or an organization that is receiving a product. The basis of this principle is that external customers are the final arbitrator who decides whether the organization will remain in business. As a result, organizations should work hard to continuously meet needs of their external customers 2 . This principle is based on the fact that management should lead as positive example to other employees of the organization, through their behaviour and approaches, thereby guaranteeing the organization's stability and its strategic direction 3. Allowing employees to reach their potential through shared values and culture of the organization, which is based on trust and empowerment of employees, supports active participation of employees in all activities of the organization 4. This principle is directly linked to the previous principle of involvement of people. It is systematic development of employee knowledge, their knowhow and skills. It is a solution to building a successful organization 5 .

The focus of this principle is the direct link to one of the effects of systematic learning in an organization. It is the current and future success on the open market. It requires creativity and ability to quickly react to all stimuli and changes 6. Experience shows that the process approach principle is necessary for creation and development of any management systems, including quality management systems. The foundation of the principle is that an organization functions more effectively and results are achieved more efficiently when mutually connected activities are understood and managed as processes 7. Following the process approach principle, we can state that identification, understanding and management of connected prin- ciples as one system leads to higher efficiency and effectiveness in reaching organizational goals. This means that a quality management system has to be a collection of connected processes 8 . We understand improvement as all activities that lead to a new and higher level of employee, process and product efficiency as well as the management system itself. Every organization has opportunities for improvement; it is only up to the organization whether it takes advantage of these opportunities 9. It is important that effective and correct decisions taken by management are based on thorough analysis of data and information and not on emotions or subjective opinions. This would lead to objective management of decisionmaking processes on all levels of management 10 . Reliability of suppliers becomes a factor that influences an organization's reach of productivity. Every organization is more effective when it develops relationships with suppliers that are based on partnerships, mutual trust, when they share know-how and integrate 11 . The last principle of modern quality management has been frequently discussed. This principle is supported by official approaches of the European Union. All organizations share responsibility for their development with their environment. Organizations provide services that are not only aligned with long-term interests of the organization, but also interests of all stakeholders.

The following areas play a key role in fulfilling this principle:

- understanding the organization's role in influencing its external environment,

- effective implementation of management systems, such as quality management systems, environmental management systems, occupational health and safety management systems, and others,

- creating conditions and environments to ensure employability of employees, which means that as part of human resources management develop special programs that help employees adapt faster to new conditions,

- support of local schools, health care, cultural and sport activities, development of the region in which the organization has long-term operations,

- systematically decrease negative impacts of organization's activities on the environment,

- use of natural resources that are available in the region, especially non-renewable resources,

- systemic communication with stakeholders and honest reporting on organization's activities and results,

- systemic evaluation of stakeholder opinions and demands,

- participation in various competitions related to productivity and quality of the organization (e.g. Slovak National Prize for Quality and Slovak National Prize for Social Responsibility).

To conclude this brief overview of basic principles of quality management, we can formulate one more principle, that is that all members of middle and upper management must actively support long-term development and application of these general principles of management in their 
organization if they do not wish to lag behind global development and do not want to cause decline of their organization, their products and processes.

\section{PRINCIPLES OF EXEPTIONALITY AS A DYBANUC FORCE AND REQUIREMENT FOR SOCIAL RESPONSIBILITY AND RESEARCH METHOD}

Basic principles of exceptionality stem from basic human rights, which is the premise for their universal application. For organizations to be successful, independent of their industry, size, structure or maturity, they need to develop an appropriate management framework. A framework that is practical and allows the organization to evaluate, on its journey to exceptionality, its key strengths and potential gaps in relation to its set vision and mission. It offers a basic structure for the organization's management system and develops common language and thinking about the organization, which will facilitate more effective communication of ideas inside of the organization and outside.

Each organization strives to be successful, some fail, some achieve partial success but eventually disappear, and there are some that achieve continuous success and get deserved respect and admiration.

Strategy for quality improvement defines widely conceived goals, key priorities and long-term goals, and maps initial initiatives. The strategy must be based on support and promotion of this effort and on building a common road to higher quality products and services. In an effort to attain a goal and to improve quality of products and services, the strategy needs to motivate and support cooperation among stakeholders on the platform of existing initiatives, including the Slovak National Prize for Quality and Slovak National Prize for Social Responsibility, and others. The strategy for improvement of quality creates opportunities to identify and to learn from those who are farther along the road to exceptionality and have improved quality or their products and services by improving their organization. The initiative to improve quality of products and services by improving the organization has to be based on clearly defined principles that help define key functions that support organization's activities, required resources and serve as supporting tools to improve quality. We are discussing eight principles of exceptionality. Application of eight principles of exceptionality, improvement of organizations by using tools and methods to achieve exceptionality are the basic measurement of organization's development. Based on the Slovak National Program of Quality for 2017-2021 (2), it is evident that organizations that identify as exceptional should focus on and implement individual principles. We expect that application of principles of exceptionality will strengthen organizations 'competitive edge, both in the public and private sectors.

\section{Focus on Results}

Organizations focus on results as they related to set goals. All parties (the government, the public and customers, partners and employees of the organization) profit from achieved goals.

\section{Focus on the Public - Customers}

Organizations focus on needs of current but also potential public-customers. They involve them in product and service development and in improvement of their performance.

\section{Leadership and Goal Stability}

This principle ties together visionary and inspirational leadership with goal stability in an ever changing environment. Leaders set a clear mission, vision and values. They create and maintain internal environment that enables full employee participation on goal achievement.

\section{Process and Data Approach Management}

This principle leads the organization. It is based on the knowledge that a desired result can be achieved more effectively when required resources and activities are managed as processes and effective decisions are based on analysis of data and information.

\section{Development and Involvement of People}

People at all levels of the organization are the foundation of the organization and their full involvement allows for use of their abilities for the benefit of the organization. Input of employees should be maximized through development and involvement, creation of a working environment that is characterized by mutually shared values, and a culture of trust and by strengthening of employees 'position and show of praise.

\section{Continuous Growth, Innovation and Improvement}

Exceptionality is a challenge to status quo and influences change with the help of continuous improvement with the goal to provide opportunities for innovation and growth. Continuous improvement therefore has to be a long-term goal for an organization.

\section{Development of Partnerships}

When trying to reach their goals, organizations need to, whether in the public or private sector, work with other organizations and must therefore develop and maintain partnerships with added value. Organizations and their suppliers are dependent on one another and mutually beneficial relationships therefore increase their ability to add value.

\section{Social Responsibility}

Public and private organizations need to take responsibility, respect environmental sustainability and have to try to meet expectations and requirement of their local and global communities.

\section{RESEARCH METHODOLOGY AND CHARAKTERISTICS OF THE SAMPLE}

In our dealings we come across a number of requirements without which a socially responsible organization could not function. We consider the following to be the basic, or fundamental, requirements: willingness, partnership with stakeholders, proactive approach, systems approach, social responsibility as part of organizational culture, triple- 
bottom line, development of life quality. When implementing social responsibility, an organization should respect principles as part of all of their activities. The following list of principles is not exhaustive, however, we consider the following principles to be fundamental. They include:

- Responsibility: speaks about responsibility an organization has, influence of its activities, decisions about the society, the environment and the economy.

- Transparency: speaks about a transparent approach of an organization to decision-making and activities that affect the society and the environment.

- Ethical behaviour: appeals to ethical behaviour of an organization, which includes fundamental values such as honesty and fairness.

- Respecting stakeholder interests: speaks about respecting and keeping in mind stakeholder interests.

- Respecting the state: this principles highlights respect towards and activities in accordance with generally applicable laws and generally binding legal requirements.

- Respecting international behavioural norms.

- Respecting human rights.

The faculty of environmental and manufacturing production, TU, in Zvolen has since 2015 dedicated systematic research of quality management as well as socially responsible enterpreneurship, their mutual connectivity and integration. We conduct research as part of research projects and we present our findings at conferences and publish them in magazines and professional publications. We will present some findings from such research projects, specifically those that are focused on integration of principles of excellence and principles of socially responsible entrepreneurship. In 2017 we conducted research focusing on integration of principles that form the foundation of quality management and socially responsible entrepreneurship. We conducted our research using focus groups as part of which we asked respondents a number of pre-selected questions. In the quantitative part of our research we focused on comperison of knowledge of socially responsible entrepreneurship and understanding of the term. Results of our research are based on responses from 1.026 citizens of Slovakia older than 18 years of age. In this article we are only considering the part of the research that dealt with principles of socially responsible entrepreneurship. Qualitative results of our research show that respondents are aware of the term socially responsible entrepreneurship and they tie it to the term responsibility (approx. 58\% of respondents) and 57\% ties it also to respect of human rights. An important finding is that they perceive socially responsible entrepreneurship as a synonym to ethical behaviour of organizations (53\%). Majority of respondents are interested in information about socially responsbile enterpreneurship, however this is not regarding primary information, but rather access to it. The discussion among the respondents showed that they understand the broad term socially responsible entrepreneurship. They understand that there are connections between organizations and their environment.

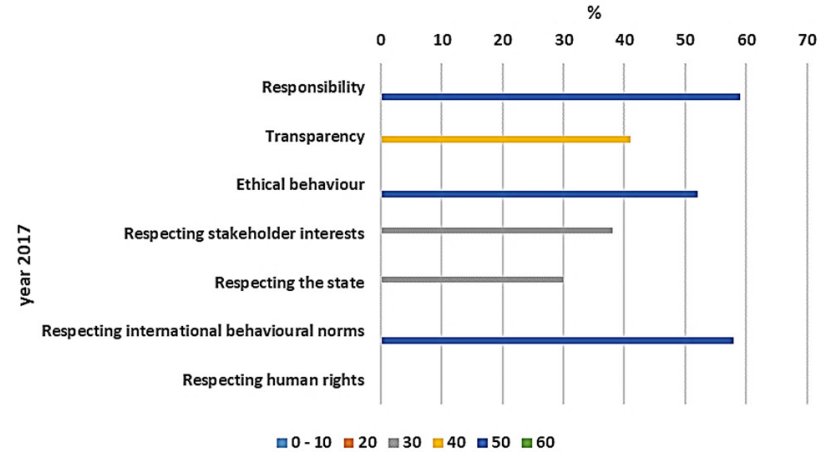

Fig. 1 Basic Principles of Corporate Social Responsibility

Increasing demands on productivity and effectivness of organizations generate desire to implement perfected management systems that take into consideration a number of processes and documents specific for a given area. A confirmation of this trend is also implementation and realization of various models of management systems specializing in quality. There is no perfect model. It is beneficial to know the tools and know what could work in the organization's environment and tie selected tools with customer demands. An organizations' exeptionality makes it stronger and helps it meet it's goals. There are organizations that fight to meet their daily reponsibilities and priorities and there are those that do not have any room to meet higher and what may be seen as abstract goals. It is advisable to identify a specific road to success. There is a model that portrays effective tools for systematic approach to implementation of social responsibility in organizations and also sets out methodology for evaluation of its level. It is the RET Model, which highlights the responsibility of management to implement features of social responsibility into management of the organization from strategy to operations. It evaluates organizational activities to ensure sustainable development, transparency, ethical behaviours towards stakeholders, participation in community development and responsible environmental behaviour.

Social responsibility management

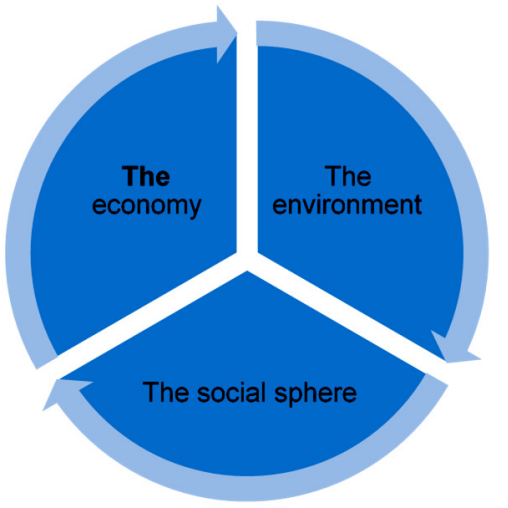

$\mathrm{R}$ - responsible

E- effective

T- transparent

\section{Fig. 2 Model RET}

Model RET is based on the quality management models, a network of GRI4 characteristics - Sustainability Reporting Guidelines created by the Global Reporting Initiative, the ISO 26000 norms - Alignment with social responsibility. 
The name of the model - RET comes from first letters of the following words:

$\mathrm{R}$ - responsible,

E - effective,

$\mathrm{T}$ - transparent.

It is responsibility towards all stakeholders (employees, the public, customers, shareholders, partners, suppliers, the government, community, etc.) and towards meeting all of their demands. In terms of staying competitive and success on the markets, as viewed based on satisfaction of all invested parties, organizational effectiveness is a key aspect. Management of all activities in the organization with systems approach in terms of process management with the help of the so called PDCA cycle (Plan - Do Check - Act), creates very good prerequisites for effective management. Transparency is closely related to sustainable development, ethics, philanthropy, contact with the media, access to information, by publishing truthful information. The model is to be used by a broad spectrum of organizations from the private or public sectors, independent of the size of the organization or its industry. It offers a way to evaluate the level of their social responsibility, whether they are initiating such activities or whether they already systematically manage such activities.

Key premise for any improvement of a quality management system of an organization is decided by upper management to improve the existing system. One possibility for an organization to meet exeptionality is to accept socially responsible entrepreneurship that is based on principles of exellence such as responsibility, transparency, ethical behaviour, respect for stakeholder interests and others. We understand socially responsible entrepreneurship as the need to cultivate inter-organizational, national and international relationships. These relationships bring value, higher quality of life, only if we understand that cultivation of relationships needs to be based on principles of exellence, including focus on customers, leadership, employee engagement, learning, flexibility and more. Figure 2 shows integration of priciples of exeptionality and socially responsible entrepreneurship with a move towards the RET model.

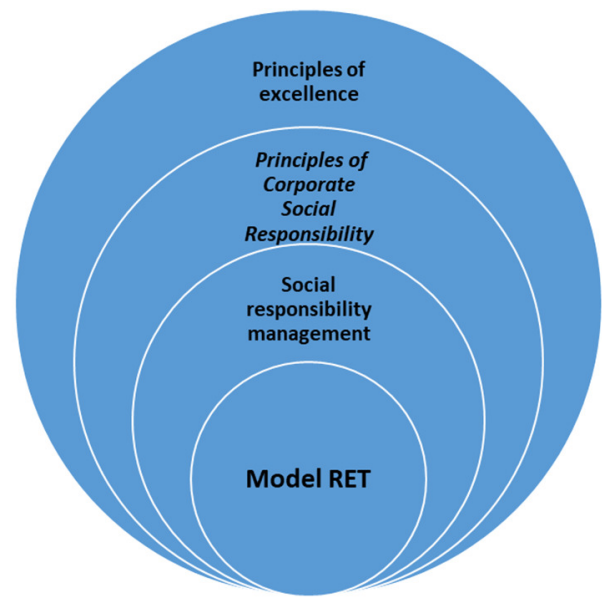

Fig. 3 Model Integrating principles of excellence and of socially responsible entrepreneurship
Principles of socially responsible entrepreneurship are closely linked to principles of exellence, that is that each organization has its leadership, ideas that are identified in the organization's vision, which are unique for the organization. Systematic and professional work with principles of exellence and socially responsible entrepreneurship bring maximum added value to all stakeholders.

\section{CONCLUSION}

For an organization to have long term and continuous success it needs to fulfill expectations of all stakeholders and as part of this we can discuss Corporate Social Responsibility - CSR. This includes behaviour of organizations that goes beyond the prescribed legislative requirements, but includes activities that benefit not only the organization itself, but also its employees and the public. This is also the basis for long-term, sustainable success.

The RET model with its balanced approach and logical connection between fundamental characteristics provides a foundation for socially responsible organizations, so that they realize that no activity or project came about by chance, but was rather a result of a planned goal, which is transparent and sustainable. The same is true for the opposite; the model does not allow an organization to perform activities that were not supported by evaluation of the impact of the activity.

\section{ACKNOWLEDGMENT}

The authors would like to thank Agency APVV for their support of the APVV-17-0400 project "Enhancing the Ethical Environment in Slovakia (Institutional Procedures, Actors, Risks, Strategies)". This article was created as part of the project.

\section{REFERENCES}

[1] B. Burg, Mann, J. D. „Giving it your all - five principles for creating a culture of Excellence“. Qual. Particip. 31 (1), 711, 2008.

[2] F. Luthans, P. J. Doh. „International Management: Culture, Strategy and'd Behavior". 7. Edition New York: The McGraw-Hill Companies, Inc.,2009. pp. 619, 14-4. 2009.

[3] E. Sujová, H. Čierna, "Corporate culture as a tool to improve safety culture" In: Management Systems in Production Engineering". Vol. 11, no. 3. pp. 49-52. 2013.

[4] H. Čierna. "Spoločensky zodpovedné podnikanie a model výnimočnosti“. Banská Bystrica UMB EF, 2008.

[5] H. Čierna, E. Sujová, M. Ťavodová. "Vybrané aspekty manažmentu pre technikov". Zvolen: TU vo Zvolene, 2015.

[6] M.J. Ligarski, "Problem identification method in certified quality management systems", Quality \& Quantity, vol. 46(1), pp. 315-321. 2012.

[7] M. Molenda, "Effectiveness of planning internal audits of the quality system", Zeszyty Naukowe Akademii Morskiej w Szczecinie, no. 32, z. 1, pp. 48-54. 2012.

[8] M. Molenda, "The intelligent integrated system management", in Proc. of the $15^{\text {th }}$ Int. Multidisciplinary Scientific GeoConference SGEM 2015 - Ecology, economics, education and legislation, Environmental economics, education $\&$ accreditation in geosciences, vol. 3, Albena, Bulgaria, pp. 681-688, 2015. 
[9] M. Molenda, I. Ratman-Kłosińska, E. Sujova, „Enviromental Technology Verification: The European Scheme as a New Quality in Validating The Performance of Ecoinnovation". [In]: $17^{\text {th }}$ International Multidisciplinary Scientific GeoConference SGEM, 2017. Conference Proceedings Volume 17. Ecology, economics, education and legislation, Issue 51. Ecology and Environmental Protection. Bulgaria, Albena, 2017.

[10] J. Nenadál, D. Noskievičová, R. Perř́ková a spol. 2008. Moderní management jakosti. Praha. ISBN 978-80-7261186-7, 2008.

[11] Národný program kvality Slovenskej republiky. 2016. Úrad pre normalizáciu mertológiu a skúšobníctvo Slovenskej republiky. www.npksr.sk/národný-program-kvality, 2016.

[12] Onwuegbuzie, A., Leech, N.: Taking the "Q" out of research: teaching research methodology courses without the divide between quantitative and qualitative paradigms. Quality \& Quantity, 39(3), 267-295, 2005.

\section{Helena Čierna}

ORCID ID: 0000-0003-2084-9282

Technical University in Zvolen

Faculty of Technology

Department of Manufacturing Technology

and Quality Management

Studentska 26, Zvolen, 960 53, Slovak Republic

e-mail: helena.cierna@tuzvo.sk

\section{Erika Sujová}

ORCID ID: 0000-0003-4281-4830

Technical University in Zvolen

Faculty of Technology

Department of Manufacturing Technology

and Quality Management

Studentska 26, Zvolen, 960 53, Slovak Republic

e-mail: erika.sujova@tuzvo.sk
[13] P. Hąbek, \& J. Brodny, "Corporate Social Responsibility Report - An Important Tool to Communicate with Stakeholders". $4^{\text {th }}$ International Multidisciplinary Scientific Conference on Social Sciences \& Arts SGEM, Conference Proceedings, Volume 5, Business and Management, Albena, Bulgaria, https://doi.org/10.5593/sgemsocial, 2017.

[14] P. Hąbek, R. Wolniak, „Assessing the quality of corporate social responsibility reports: the case of reporting practices in selected European Union member states", Quality \& Quantity, vol. 50 (1), pp 399-420, 2016.

[15] P. Hąbek. „Evaluation of sustainability reporting practices in Poland“. Quality \& Quantity. 48(3), 1739-1752, 2014.

[16] R. Mullerat. International Corporate Social Responsibilizy: The Role of Corpirations in the Economic Order of the 21 $1^{\text {st }}$ Century. Kluwer Law Intrernational, pp 510. ISBN 978-904-11-2590-3, 2010.

[17] R.W.Griffin, M.W.Pustay. „International business: A managerial perspective". 5. Edition Pheonix: Quebecor World Versailles. pp 632, 2007. 